\title{
DIAGNOSTIC ACCURACY OF SALINE HYSTEROSONOGRAPHY IN DETECTING ENDOMETRIAL HYPERPLASIA IN PATIENTS WITH POSTMENOPAUSAL BLEEDING
}

\author{
Beenish Yousuf ${ }^{a}$, Hira Ambreen ${ }^{b}$, Tahira Mariam ${ }^{c}$, Abdul Raouf ${ }^{d}$, Ambreen Yaseen ${ }^{a}$, Rabia Aslamb ${ }^{b}$ Muhammad \\ Ahsan $^{\text {e }}$ \\ ${ }^{a}$ Women Medical officer, Department of Obstetrics \& Gynecology, Government General Hospital, Faisalabad. \\ ${ }^{\mathrm{b} C o n s u l t a n t}$ Gynecologist DHQ Hospital, Chiniot. \\ 'Women Medical officer THQ Hospital Chichawatni. \\ ${ }^{\mathrm{d} A s s i s t a n t}$ Professor, Department of Radiology, Faisalabad Medical University, Faisalabad. \\ ${ }^{\mathrm{e}}$ Medical Officer, Department of Pediatrics, Government General Hospital, Faisalabad.
}

\begin{abstract}
:
BACKGROUND \& OBJECTIVE: Saline hysterosonography is a simple and cost-effective method with high sensitivity to detect uterine abnormalities causing postmenopausal bleeding. The objective of this study was to evaluate the diagnostic accuracy of saline hysterosonography in detecting endometrial hyperplasia in women with postmenopausal bleeding by taking histopathology as a gold standard.

METHODOLOGY: A hundred and twenty (120) cases were enrolled from the outpatient and inpatient department of obstetrics and gynecology. Proper history and relevant examination of the patient was done. Then preparations were made for the procedure. The patient was counseled and the technique explained to her. Then Foley catheter no 12 was passed in cervix and sonography was done while instilling normal saline through a cervical catheter and scan pictures were frozen and results were given by expert gynecologist of Allied Hospital, Faisalabad. Histopathology specimen was sent to the pathology lab.

RESULTS: Sensitivity, specificity, positive predictive value, negative predictive value, and diagnostic accuracy of saline hysterosonography in detecting endometrial hyperplasia was recorded as $96.15 \%, 91,49 \%, 75.76 \%, 98.85 \%$, and $92.5 \%$ respectively.

CONCLUSION: Saline hysterosonography has high sensitivity to detect uterine hyperplasia. It can be used as a cost effective alternative to hysteroscopy in many units in Pakistan.

KEYWORDS: Saline hysterosonography, Endometrial hyperplasia, Postmenopausal bleeding.
\end{abstract}

doi: https://doi.org/10.37723/jumdc.v11i2.304

How to cite this:

Yousuf B, Ambreen H, Mariam T, Raouf A, Yaseen A, Aslam R, Ahsan M. DIAGNOSTIC ACCURACY OF SALINE HYSTEROSONOGRAPHY IN DETECTING ENDOMETRIAL HYPERPLASIA IN PATIENTS WITH POST MENOPAUSAL BLEEDING. jumdc. 2020;11(2):1-8.

doi: https://doi.org/10.37723/jumdc.v11i2.304

This is an Open Access article distributed under the terms of the Creative Commons Attribution License (http://creativecommons.org/licenses/by/4.0), which permits unrestricted use, distribution, and reproduction in any medium, provided the original work is properly cited. 


\section{INTRODUCTION:}

Postmenopausal bleeding (PMB) occurs in approximately $3 \%$ of postmenopausal women

${ }^{[1]}$. Abnormal bleeding is the cause behind 33\% of all admissions to gynecology center and $69 \%$ among postmenopausal women ${ }^{[2]}$. Excessive bleeding occurring outside of regular menstrual cycle in which two-third of all hysterectomies is accounted for is characterized as abnormal uterine bleeding ${ }^{[3]}$. Simple atrophic vaginitis to endometrial carcinoma in postmenopausal women is the reason for abnormal bleeding. The most common lesions resulting in abnormal uterine bleeding are endometrial polyps, uterine fibroids, endometrial hyperplasia ${ }^{[4]}$. Surgical treatment may be required for them. While medical treatment is required for dysfunctional causes ${ }^{[2]}$.

The chance of having endometrial carcinoma for patients with PMB is $10-15 \%{ }^{[5]}$. For women over the age of 40 with abnormal uterine bleeding, the clinician's vital task is to exclude endometrial carcinoma ${ }^{[6]}$. The excessive proliferation of normal cells can be characterized by the term endometrial hyperplasia. It can further be ordered into three types: simple, complex, and atypical. The development rate of malignancy is less than $3 \%$ for both simple and complex types due to premalignant conditions. In various arrangements, the risk of underlying malignancy has demonstrated to be higher than anticipated. So it is very important to detect it as early as possible to make decisions regarding surgery if the patient is high risk or follow up in low-risk cases ${ }^{[7]}$. In a previous study, the prevalence of endometrial hyperplasia was $26 \%{ }^{[1]}$.

For the analysis of uterine abnormality leading to postmenopausal bleeding, an assortment of tools can be utilized. Among these, for the evaluation of abnormalities of the uterine cavity, hysteroscopy is considered the gold standard ${ }^{[8]}$.

In postmenopausal women, transvaginal sonography (TVS) is an effective screening test for the evaluation of abnormal uterine bleeding caused by endometrial atrophy ${ }^{[9]}$. But in the figure of thickened and inhomogeneous endometrium, TVS is presented as low specificity and limited diagnostic tests which
Corresponding Author:

Dr. Muhammad Ahsan

Medical Officer, Govt General Hospital, Faisalabad. I Email: ahsanjahangir194@gmail.com

can be replaced by saline contrast sonohysterography (SCSH) ${ }^{[10]}$. Saline contrast sonohysterography or saline hysterosonography (SCHS) can be considered as a primary diagnostic method in the detection of uterine cavity abnormalities ${ }^{[11]}$. It seems that SCSH is a noninvasive, cost-effective, and feasible technique and less painful for patients than hysteroscopy [12]. Saline hysterosonography has become a valuable diagnostic modality in gynecology over the last three decades and is now commonly used for a thorough evaluation of the lesions in the endometrial cavity ${ }^{[13,14]}$.

The rationale of this study is to introduce a simple and noninvasive investigation tool to detect endometrial abnormalities in patients with postmenopausal bleeding and its effect on clinical administration. The objective of this cross-sectional (validation) study was to assess the diagnostic accuracy of saline hysterosonography in detecting endometrial hyperplasia in women with postmenopausal bleeding by taking histopathology as a gold standard.

\section{METHODOLOGY:}

The study has been approved by the ethical review committee of Faisalabad Medical University, Faisalabad. Postmenopausal bleeding was diagnosed when a woman after menopause, presented with complaints of pervaginal bleeding that may range from spotting to a massive pool of blood. Menopause is defined as the last menstrual period after a minimum of 1-year amenorrhea and her age $>50$.

With saline hysterosonography endometrial hyperplasia, typically appear as diffuse thickening of the endometrium with endometrial thickness $5 \mathrm{~mm}$ to $8 \mathrm{~mm}$. On histopathology of the biopsy specimen, endometrial hyperplasia is characterized by mild to marked increase in several glands of different sizes and unpredictable shapes with 
cystic dilatation, with mild to a marked escalation in gland to stroma ratio and glandular epithelial cells may or may not have cytologic atypia as defined by loss of polarity, vesicular nuclei, and prominent nucleoli.

Sensitivity is the proportion of true positives out of all those who truly have the endometrial hyperplasia. Specificity is the proportion of true negatives out of all those who truly don't have the endometrial hyperplasia. Positive predictive value is the proportion of true positives out of all those who are positive on saline hysterosonography. Negative predictive value is the proportion of true negatives out of all those who are negative on saline hysterosonography. True positives (TP) are those individuals who are positive on saline hysterosonography as well as on histopathology. True negatives (TN) are those individuals who are negative on saline hysterosonography as well as histopathology. False positives (FP) are those individuals who are positive on saline hysterosonography but negative on histopathology. False negatives (FN) are those individuals who are negative on saline hysterosonography but positive on histopathology.

It was conducted in the Department of obstetrics and gynecology, Allied Hospital, Faisalabad after 6 months of synopsis approval. Sample size 120 was calculated using sample size calculator for sensitivity and specificity, taking Sensitivity $=92 \%$, Specificity $=78 \%$, expected prevalence of endometrial hyperplasia of $26 \%$ and confidence level $=95 \%$, precision for sensitivity $=8 \%$, for specificity = $10 \%$. Sampling was done using non-probability consecutive sampling. All postmenopausal women with age $>50$ years having postmenopausal bleeding were included in the study. The following were excluded: already diagnosed cases of cervical carcinoma, pyometra, and hematomata; patients with acute pelvic infection, acute uterine hemorrhage, and diagnosed cases of endometrial cancer.

After taking approval from the hospital ethical committee, patients presenting in the gynecological outpatient and inpatient department, fulfilling the inclusion criteria for the study were enrolled. The identity of patients was recorded and informed consent was taken from patients or their guardians to incorporate the information in research work.

After receiving patients in the outpatient department or after admission in ward, proper history and relevant examination of the patient were done. Then preparation was made for the procedure. The patient was counseled and the technique explained to her. Foley's catheter no 12 was passed in cervix and sonography was done while instilling normal saline through a cervical catheter and scan pictures were frozen and results were given by expert gynecologist of Allied Hospital, Faisalabad. Regarding histopathology specimen, it was sent to the Pathology laboratory in Faisalabad Medical University where results were given by expert pathologist.

All the data were analyzed by SPSS version- 23 . Quantitative variables like age endometrial thickness were presented by the mean and standard deviation. Frequency and percentage were presented for qualitative variables like true positives. Sensitivity, specificity, positive predictive value, negative predictive value, and diagnostic preciseness were determined by building two into two tables by taking histopathology as the highest level standard.

\section{RESULTS:}

Age distribution of the patients showed that $76.7 \%(n=92)$ were in Group-A i.e. between $50-60$ years of age and $23.3 \%(n=28)$ were in Group-B i.e. between $61-70$ years of age (Table-I). Mean age and endometrial thickness of the patients were calculated. The mean \pm SD for age and endometrial thickness was calculated as $57.18 \pm 4.92$ years and $3.99 \pm$ $1.54 \mathrm{~mm}$ respectively (Table-II).

Sensitivity, specificity, positive predictive value, negative predictive value, and diagnostic accuracy of saline hysterosonography in detecting endometrial hyperplasia was recorded as $96.15 \%, 91,49 \%, 75.76 \%$, $98.85 \%$ and $92.5 \%$ respectively (Table-III).

Regarding age distribution, Sensitivity, specificity, positive predictive value, negative predictive value and diagnostic accuracy of saline hysterosonography in detecting endometrial hyperplasia in group $\mathrm{A}$ i.e. between 
$50-60$ years of age were recorded as $100 \%$, $97.6 \%, 80 \%, 100 \%$, and $97.8 \%$ respectively, while these values for Group-B i.e. between 61-
70 years of age were recorded as $94.4 \%, 40 \%$, $73.9 \%, 80 \%$ and $75 \%$ respectively (Table -IV).

Table-I: Age Distribution $(n=120)$.

\begin{tabular}{|c|c|c|c|}
\hline \multicolumn{2}{|c|}{ Groups } & Frequency & Percent \\
\hline A & $50-60$ years & 92 & 76.7 \\
\hline B & $61-70$ years & 28 & 23.3 \\
\hline \multicolumn{2}{|c|}{ Total } & 120 & 100.0 \\
\hline
\end{tabular}

Table-II: Mean age \& endometrial thickness.

\begin{tabular}{|c|c|c|c|c|c|}
\hline & $\mathbf{N}$ & Minimum & Maximum & Mean & Std. Deviation \\
\hline Age & 120 & 51 & 70 & 57.18 & 4.922 \\
\hline $\begin{array}{c}\text { Endometrial } \\
\text { Thickness }\end{array}$ & 120 & 2.00 & 9.00 & 3.9958 & 1.54008 \\
\hline
\end{tabular}

Table-III: Diagnostic accuracy of Saline Hysterosonography

\begin{tabular}{|c|c|c|c|c|}
\hline \multirow{2}{*}{} & \multicolumn{2}{|c|}{$\begin{array}{c}\text { Endometrial hyperplasia on } \\
\text { histopathology }\end{array}$} & \multirow{2}{*}{ Total } \\
\cline { 3 - 5 } & & Yes & No & \\
\hline $\begin{array}{c}\text { Endometrial hyperplasia on } \\
\text { saline hysterosonography }\end{array}$ & Yes & 25 & 86 & 33 \\
\cline { 2 - 5 } & No & 1 & 94 & 120 \\
\hline \multicolumn{2}{|c|}{ Total } & 26 & 86 & 94 \\
\hline
\end{tabular}

Sensitivity $=96.15 \%$

Specificity $=91.49 \%$

PPV $=75.76 \%$

NPV $=98.85 \%$

Diagnostic accuracy $=92.5 \%$

Table-IV: Diagnostic accuracy of saline hysterosonography in different age groups.

\begin{tabular}{|c|c|c|c|c|c|c|}
\hline \multirow[t]{2}{*}{$\begin{array}{c}\text { Age } \\
\text { Distribution }\end{array}$} & & & \multicolumn{2}{|c|}{$\begin{array}{c}\text { Endometrial } \\
\text { hyperplasia on } \\
\text { histopathology }\end{array}$} & \multirow{2}{*}{ Total } & \\
\hline & & & Yes & No & & \multirow{4}{*}{$\begin{array}{c}\text { Sensitivity = } \\
100 \% \\
\text { Specificity = } \\
97.6 \% \\
\text { PPV }=80 \% \\
\text { NPV }=100 \% \\
\text { DA }=97.8 \%\end{array}$} \\
\hline \multirow{3}{*}{$\begin{array}{c}\text { Group- } A \\
50-60 \text { years }\end{array}$} & \multirow{2}{*}{$\begin{array}{c}\text { Endometrial } \\
\text { hyperplasia on saline } \\
\text { hysterosonography }\end{array}$} & Yes & 8 & 2 & 10 & \\
\hline & & No & 0 & 82 & 82 & \\
\hline & \multicolumn{2}{|l|}{ Total } & 8 & 84 & 92 & \\
\hline \multirow{3}{*}{$\begin{array}{c}\text { Group-B } \\
61-70 \text { years }\end{array}$} & Endometrial & Yes & 17 & 6 & 23 & \multirow{3}{*}{$\begin{array}{c}\text { Sensitivity = } \\
94.4 \% \\
\text { Specificity = } \\
40 \% \\
\text { PPV }=73.9 \% \\
\text { NPV }=80 \% \\
\text { DA }=75 \%\end{array}$} \\
\hline & $\begin{array}{l}\text { hyperplasia on saline } \\
\text { hysterosonography }\end{array}$ & No & 1 & 4 & 5 & \\
\hline & \multicolumn{2}{|l|}{ Total } & 18 & 10 & 28 & \\
\hline
\end{tabular}




\section{DISCUSSION:}

A common presenting complaint of patients in gynecology department is postmenopausal bleeding. In postmenopausal patients due to diffuse endomyometrial border, endometrium is more difficult to measure. With the addition of cutting-edge imaging modalities, the evaluation and management of postmenopausal bleeding are evolving rapidly. Transvaginal sonography (TVS) is a first-line insightful methodology in the assessment of postmenopausal bleeding; however, it has restricted an incentive in assessment and differential determination of intra-cavitary unusual pathologies. For women with postmenopausal bleeding, hysteroscopy (HS) and saline hysterosonography are alternative diagnostic procedures and are more effective in the detection of intra-cavitary abnormal pathologies than TVS. While saline hysterosonography is cost-effective and noninvasive, diagnostic HS is still generally accepted as the gold standard for the evaluation of the uterine cavity. It is an invasive procedure, which is associated with discomfort for the patients and sometimes a vasovagal attack [15,16].

This study was conducted with the purpose to establish the indicative accuracy of saline hysterosonography in postmenopausal patients. As patients with immeasurable endometrium often harbor cancer so these patients were included in the study.

In this study, $5 \mathrm{~mm}$ cut-off was used. All the ladies with abnormal saline hysterosonography had diagnostic or therapeutic procedures. De Kroon et al ${ }^{[17]}$ did a meta-analysis of diagnostic accuracy of SCHS among women reporting with abnormal uterine bleeding. Two studies used $>5$ $\mathrm{mm}$ cutoff and one used $>6 \mathrm{~mm}$ cut-off, all at variance with this study with a cut-off of $5 \mathrm{~mm}$. The sensitivity and specificity in these studies were $96 / 92 \%, 100 / 95 \%$, and $89 / 50 \%$ respectively. The present results of $96.15 \%$ sensitivity and $91.49 \%$ specificity are close to the pooled result of de Kroon's meta-analysis $95 \%$ for sensitivity $88 \%$ for specificity ${ }^{[10]}$. In another study, the same results of $95 \%$ sensitivity and $88 \%$ specificity were found ${ }^{[6]}$.

For the screening of intracavitary pathologies, a useful procedure is hysterosonography it allows differentiation of intracavitary, endometrial, and sub-mucosal abnormalities. Saline hysterosonography was abnormal in all cases of endometrial carcinoma in the current study. There was a good comparison between hysteroscopy and saline hysterosonography where the former was the gold standard. The accuracy of hysteroscopy and saline hysterosonography was almost equal though saline hysterosonography is less expensive and better tolerated ${ }^{[18]}$. Also in our unit, only indoor hysteroscopy is available. Many studies have confirmed that saline hysterosonography is as good as hysteroscopy under general anesthesia at detecting/excluding focal lesions. Hydrosonography is less painful and costeffective than hysteroscopy ${ }^{[19]}$. In many units in Pakistan, hysteroscopy is not available. Hence the latter can be replaced in the local setting by saline hysterosonography. Saline hysterosonography greatly reduces the number of unnecessary hysteroscopy as it is only indicated where focal lesions need further evaluation/removal.

In another study, the sensitivity and specificity of saline hysterosonography were $92.9 \%$ and $89.7 \%{ }^{[20]}$ respectively which is also in agreement with our results. But in another study ${ }^{[8]}$, these results were different i.e. $82 \%$ sensitivity and 95 specificity. Still, two other studies, ${ }^{[21,22]}$ showed a sensitivity of $71.4 \%$ and 89.3 and specificity of $82.3 \%$ and $77.3 \%$.In these studies, overall sensitivities and specificities are less than that found in our study specificity is more than sensitivity in the first two studies whereas sensitivity is more in the last study which is in agreement with our study. Initial two examinations are directed in women with unusual uterine bleeding of all ages but the last study was conducted in women with postmenopausal bleeding. This may be the reason for this difference found in these studies. The learning curve of saline hysterosonography is considered to be very short for those familiar with gynecological ultrasound. Failure is almost always due to cervical stenosis. In the present series, poor cavity distension was found in cases of endometrial cancer and the same was observed earlier. Distension difficulties in saline hysterosonography raise the suspicion of carcinoma. The detection rate of Doppler ultrasound is slightly lower than that for saline 
infusion, whereas the false-positive rate of Doppler is around five times higher. The clinical value of $3 D$ ultrasound is a matter of current debate ${ }^{[17]}$.

Chawla I et al showed the sensitivity of $89.1 \%$ and specificity of $100 \%$. NPV of $73.7 \%$ and PPV of $100 \%{ }^{[23]}$. Kasidag et al mentioned the sensitivity, specificity, PPV, and NPV to be $93 \%$, $53 \%, 86 \%$, and $71 \%$ respectively in the case of saline hysterosonography ${ }^{[24]}$. The pooled sensitivity of saline hysterosonography in the detection of intrauterine abnormalities was 0.88 . The pooled specificity was 0.94 . SCHS also had a high pooled sensitivity and specificity in the detection of congenital uterine anomalies, 0.85 and 1 [95\% CI 0.99- 1] respectively ${ }^{[25]}$. Mathew et al ${ }^{[26]}$ concluded that saline infusion sonohysterography is a simple evaluating method with minimal invasiveness and cost which is more accurate than TVS and can be done as a screening tool before hysteroscopy. It is now accepted that Saline infusion sonohysterography also is a reliable method for evaluation of endometrial lesions and after saline hysterosonography appropriate treatment can be planned ${ }^{[27]}$.

Saline hysterosonography could not differentiate benign from malignant lesions. But saline hysterosonography helps in choosing the patient where operative hysteroscopy is required. Saline infusion sonography (SIS) and 3D-SIS were correspondingly precise in assessing the histological nature, intrauterine degree, and area of intrauterine abnormalities. The dependability of 3D-SIS was good: intraobserver and inter-observer agreement were 0.78 and 0.72 . They concluded that threedimensional saline infusion sonography is legitimate and dependable for women suspected of having intrauterine variations from the norm (abnormalities). It may have relevant clinical value in addition to conventional saline hysterosonography as the endometrial cavity is three dimensional ${ }^{[17]}$.

In a study published in a local journal, it was reported that saline hysterosonography has a specificity of $96 \%$, the sensitivity of $60 \%$, positive predictive value (PPV) $87.8 \%$, negative predictive value (NPV) $83.3 \%$, and the accuracy rate was $87 \%$ for endometrial lesions. For TVS, PPV was $75 \%$. They concluded that saline hysterosonography should be performed in patients before hysteroscopy because it will protect a considerable number of patients from unnecessary invasive procedures ${ }^{[28]}$.

We are also of the opinion that saline hysterosonography should be done for all patients with suspected endometrial hyperplasia. Further studies should also be done at other centers in our local population regarding the role of saline hysterosonography in the diagnosis of endometrial lesions including hyperplasia.

\section{CONCLUSION:}

Saline hysterosonography has high sensitivity to detect uterine hyperplasia. It can be used as a cost effective alternative to hysteroscopy in many units in Pakistan.

\section{CONFLICT OF INTEREST:}

All authors disclose no conflict of interest.

GRANT SUPPORT \& FINANCIAL DISCLOSURES: None.

\section{REFERENCES:}

1. Choudry A, Shukr I, Khan S, Hafeez H, Jamal S, Anwer A. Acceptability and accuracy of saline infusion sonohysterography in women with postmenopausal bleeding. Journal of College of Physicians and Surgeon Pakistan 2010; 20: 571-575.

2. Abdelazim IA, Abdelrazak KM, Elbiaa AA, Al-Kadi M, Yehia AH. Accuracy of endometrial sampling compared to conventional dilatation and curettage in women with abnormal uterine bleeding. Archives of gynecology and obstetrics. 2015;291(5):1121-1126. Doi:10.1007/ s00404-014-3523-y.

3. Kotdawala P, Kotdawala S, Nagar N. Evaluation of endometrium in perimenopausal abnormal uterine bleeding. Journal of mid-life health. 2013;4(1):1621. doi: 10.4103/0976-7800.109628 PMID: 23833528.

4. Nieuwenhuis LL, Hermans FJ, de Vaate AM, Leeflang MM, Brölmann HA, Hehenkamp $W J$, et al. Three dimensional saline 
infusion sonography compared to two dimensional saline infusion sonography for the diagnosis of focal intracavitary lesions. Cochrane Database of Systematic Reviews. 2017 (5). Doi:10.1002/14651858.CD011126.pub2.

5. Mishra. B, Singh V, Sahu M and Sinha S. Comparative study on saline infusion sonography vs. conventional ultrasound in evaluation of endometrial pathology, in patients with abnormal uterine bleeding. International Journal of Current Inovation Research. 2018; 4:996-1001. DOI: 10.24327/IJCIR.

6. Renjhen P, Kanagasabai S. Role of sonohysterography in evaluation of abnormal uterine bleeding. The Internet Journal of Gynecology and Obstetrics. 2009 [cited 2009];13(2). Available from; http://ispub.com/IJGO/13/2/8371.

7. Kehoe S. Endometrial cancer. In: Edmonds DK, editor. Dewhurst's textbook of obstetrics \& gynaecology. $8^{\text {th }}$ ed. London: Wiley-Blackwell; 2012:776-782.

8. Reddi RP, Lakshmikantha G. Transvaginal sonography (TVS) and saline infusion sonohysterography (SIS) in the evaluation of abnormal uterine bleeding (AUB). The journal of Obstetrics and Gynecology of India. 2010;60(6):511-515.

9. Karlsson B, Granberg S, Wikland M, Ylöstalo $\mathrm{P}$, Torvid K, Marsal K, et al. Transvaginal ultrasonography of the endometrium in women with postmenopausal bleeding-a Nordic multicenter study. American journal of Obstetrics and Gynecology. 1995; 172: $1488-94$ DOI : $10.1016 / 0002$ 9378(95)90483-2. PMID: 7755059.

10. De Kroon CD, de Bock GH, Dieben SW, Jansen FW. Saline contrast hysterosonography in abnormal uterine bleeding: a systematic review and meta analysis. BJOG: An International Journal of Obstetrics \& Gynaecology. $2003 ; 110(10): 938-947$. Doi : 10.1111/j.1471-0528.2003.02472.x. PMID: 14550365.

11. Luterek K, Szymusik I, Bartkowiak R, Wielgos M. Sonohysterography in peri-and postmenopausal women with abnormal uterine bleeding or abnormal endometrial appearance. Neuro Endocrinology letters.
2014;35(4): 297-300. PMID: 25038603.

12. Tangri MK, Srivastava AK. Diagnostic accuracy of saline infusion sonography as compared to hysteroscopy in premenopausal women with abnormal uterine bleeding. International Journal of Reproduction Contraception, Obstetrics and Gynecology. 2017;6(2):682-687. DOI: 10.18203/2320-1770.ijrcog20170405.

13. Loiacono RM, Trojano G, Del Gaudio N, Kardhashi A, Deliso MA, Falco G, et al. Hysteroscopy as a valid tool for endometrial pathology in patients with postmenopausal bleeding or asymptomatic patients with a thickened endometrium: hysteroscopic and histological results. Gynecologic and Obstetric Investigation. 2015;79(3):210216. DOI: $10.1159 / 000371758$ PMID: 25765014.

14. Zafar H, Naz M, Fatima U. Diagnostic accuracy of saline sonohysterography for evaluation of uterine cavity abnormalities in patients with abnormal uterine bleeding. The Professional Medical Journal. 2019; 26(6):892-895. DOI: $10.29309 / T P M J /$ 2019.26.05.3589.

15. Abbas A, Khalaf M, Tammam AA, Hashim A, Mwafy $A$. The diagnostic value of saline infusion sonohysterography versus hysteroscopy in evaluation of uterine cavity in patients with infertility and recurrent pregnancy loss. Thai Journal of Obstetrics and Gynaecology. 2015:113-117.

16. Draz MH, El-Sabaa TM, El Shorbagy SH. Saline infusion sonography versus hysteroscopy in the evaluation of uterine cavity in women with unexplained infertility. Tanta Medical Journal. 2017;45(3):155-159.

17. De Kroon CD, Louwé LA, Trimbos JB, Jansen FW. The clinical value of 3 dimensional saline infusion sonography in addition to 2 dimensional saline infusion sonography in women with abnormal uterine bleeding: work in progress. Journal of ultrasound in Medicine. 2004;23(11):1433-1440.

18. Timmermans A, Opmeer BC, Veersema $S$, Mol BW. Re: Pain experienced during transvaginal ultrasound, saline contrast sonohysterography, hysteroscopy and office sampling: a comparative study. Ultrasound in Obstetrics \& Gynecology. 
2008;32(1):118-119. Doi:10.1002/ uog.5367.

19. Bittencourt CA, dos Santos Simões R, Bernardo WM, Fuchs LF, Soares Júnior JM, Pastore AR, et al. Accuracy of saline contrast sonohysterography in detection of endometrial polyps and submucosal leiomyomas in women of reproductive age with abnormal uterine bleeding: systematic review and meta analysis. Ultrasound in Obstetrics \& Gynecology. 2017;50(1):32-39.

20. Aslam M, Ijaz L, Tariq S, Shafqat K, Nisa MU, Ashraf R, et al. Comparison of Transvaginal Sonography and Saline Contrast Sonohysterography in Women. International Journal of Health Sciences. 2007;1(1):17-24.

21. Karimzadeh MA, Firouzabadi RD, Goharzad F. Diagnostic value of saline contrast sonohysterography comparing with hysteroscopy for detecting endometrial abnormalities in women with abnormal uterine bleeding. Iranian journal of reproductive medicine. 2011;9(3):199202. PMID: 26396564.

22. Bingol B, Gunenc MZ, Gedikbasi A, Guner $\mathrm{H}$, Tasdemir S, Tiras B. Comparison of diagnostic accuracy of saline infusion sonohysterography, transvaginal sonography and hysteroscopy in postmenopausal bleeding. Archives of gynecology and obstetrics. 2011;284 (1):111-117.

23. Chawla I, Tripathi S, Vohra P, Singh P. To evaluate the accuracy of saline infusion sonohysterography (SIS) for evaluation of uterine cavity abnormalities in patients with abnormal uterine bleeding. The Journal of Obstetrics and Gynecology of India. 2014;64(3):197-201.

24. Seshadri S, El-Toukhy T, Douiri A, Jayaprakasan K, Khalaf Y. Diagnostic accuracy of saline infusion sonography in the evaluation of uterine cavity abnormalities prior to assisted reproductive techniques: a systematic review and meta-analyses. Human reproduction update. $2015 ; 21(2): 262$ 274.
25. Seshadri S1, El-Toukhy T2, Douiri A3, Jayaprakasan K4, Khalaf Y2 2015 MarApr;21(2):262-274. doi: 10.1093/ humupd/dmu057. Epub 2014.

26. Mathew M, Gowri V, Rizvi SG. Saline infusion sonohysterography-an effective tool for evaluation of the endometrial cavity in women with abnormal uterine bleeding. Scandinavian Association of Obstetricians and Gynaecologists. 2010;89(1):140-142.

27. El-Sherbiny W, El-Mazny A, Abou-Salem $\mathrm{N}$, Mostafa WS. The diagnostic accuracy of two-vs three-dimensional sonohysterography for evaluation of the uterine cavity in the reproductive age. Journal of Minimally Invasive Gynecology. 2015;22(1):127-131.

28. Ogutcuoglu B, Karadag C, Inan C, Dolgun ZN, Yoldemir AT, Aslanova L. Diagnostic utility of saline infusion doppler sonohysterography in endometrial mass lesions. Pakistan Journal of Medical Sciences. 2016;32(2):284-288. Doi: 10.12669/pjms.322.9452 PMID: 27182224.

\section{Authors' Contribution:}

Beenish Yousuf: Data collection, study design, manuscript writing and proof reading.

Hira Ambreen: Data collection, analysis and manuscript writing.

Tahira Mariam: Data collection, statistical analysis and literature search.

Abdul Raouf: Data collection, analysis and final draft of study.

Ambreen Yaseen: Manuscript writing and proof reading.

Rabia Aslam: Manuscript writing and data collection.

Muhammad Ahsan: Manuscript writing and data collection.

Submitted for publication: 25.11.2019

Accepted for publication: $\quad 06.06 .2020$

After Revision 